\title{
A PAJELANÇA CABOCLA: ASPECTOS DA TRADUÇÃO ENTRE A FEITIÇARIA E XAMÃS
}

\author{
Roseanne Castelo Branco ${ }^{1}$
}

\begin{abstract}
RESUMO
O presente trabalho consiste em abordar o caráter da tradução no universo da linguagem resultante do estudo sobre a representação do imaginário amazônico presente nas narrativas de Zeneida Lima (1992; 2001), pajé oriunda da ilha do Marajó, na sua inter-relação com os caruanas ou encantados. A investigação aborda os aspectos antropológicos de humanos e não humanos sob a ótica de teóricos como Câmara Cascudo (1956), Viveiros de Castro (1993), Lévi-Strauss (2003), Evelyn Zea (2008) e Bruna Franchetto (2012), assim como são consideradas, no âmbito da tradução, as idéias de filósofos e teóricos como Walter Benjamin (2008), Paul De Man (1989), Derrida (1972) e Venuti (1995). No contexto da narrativa sobre a pajelança cabocla, a pajé Zeneida Lima recebe, em sessões mediúnicas, seres não-humanos entrando num processo de transe e êxtase, onde conta com a presença de um tradutor denominado na narrativa de 'transmissor', que traduz a língua dos encantados para o entendimento dos homens que habitam a terra, numa dimensão cosmológica.
\end{abstract}

Palavras-Chave: Pajelança. Tradução. Encantados

\begin{abstract}
The present work consists in approaching the character of the translation in the universe of the language resulting from the study on the representation of the Amazonian imaginary present in the narratives of Zeneida Lima (1992, 2001), a pajé from the island of Marajó, in its interrelation with Caruanas or enchanted. The research deals with the anthropological aspects of humans and nonhumans from the standpoint of theoreticians such as Câmara Cascudo (1956), Viveiros de Castro (1993), LéviStrauss (2003), Evelyn Zea (2008) and Bruna Franchetto (2012) As are the ideas of philosophers and theorists such as Walter Benjamin (2008), Paul De Man (1989), Derrida (1972) and Venuti (1995). In the context of the narrative on the pajelança cabocla, the pajé Zeneida Lima receives, in mediumistic sessions, nonhuman beings entering a process of trance and ecstasy, where it counts on the presence of a translator called in the narrative of 'transmitter', which translates to Language of the enchanted to the understanding of the men who inhabit the earth, in a cosmological dimension.
\end{abstract}

Keywords: Pajelança. Tradudion. Encantados.

Recebido em: 21/04/ 2017

Aprovado em: 10/05/2017

A pajelança não é religião e eu não sou bruxa ${ }^{2}$ Chegaram a dizer que eu virava bode em noite de lua cheia! ${ }^{3}$

A Amazônia se encontra no imaginário da maioria das pessoas em todos os continentes, como a vastidão das águas, densa floresta e animais silvestres. A natureza parece

\footnotetext{
${ }^{1}$ Mestra em Estudos Literários - Universidade Federal do Pará (UFPA). Professora de Teoria Literária, Língua e Literatura alemãs. Doutoranda do Programa de Pós-Graduação em Estudos da Tradução (DINTER/UFSC/UFPA). E-mail: rosannecb@yahoo.com.br

${ }^{2}$ http://revistamarieclaire.globo.com/Marieclaire/0,6993,EML1699287-2455,00.html. Acesso em: 23 set. 2016

3 Lima,Zeneida. O Mundo Místico dos Caruanas,Cejup,1992, p.23.
} 
viver uma relação de comprometimento entre a vida animal, vegetal e humana. Presença marcante das lutas entre o nativo e o conquistador. Na opinião de Ianni (apud Loureiro, 1995, p.7), a Amazônia, para alguns, seria o paraíso perdido ou o eldorado escondido. Tudo se resume em um emaranhado de contos, mitos e lendas. Adentrar no mundo amazônico é sentir o aroma das ervas, sentir a magia das águas e da floresta e se deixar envolver pelos mitos e sincretismo religioso, oriundo do mundo indígena, africano e europeu.

É no mundo imaginário amazônico, mais precisamente, na ilha do Marajó, que se ouve falar da história da pajé, Zeneida Lima, cuja história é narrada em dois momentos e relatada nas obras O Mundo Místico dos Caruanas e a Revolta de sua Ave (1992) e O Mundo Místico dos Caruanas na Ilha do Marajó (2001). Sob a ótica da crítica literária trata-se de uma obra autobiográfica, no entanto para alguns estudiosos, apresenta material de pesquisa antropológico. Este trabalho investiga a abordagem da tradução do universo da linguagem dos caruanas (entidades/encantados), resultantes de manifestações mediúnicas, contando com o apoio de idéias de teóricos da tradução e da antropologia.

D. Zeneida, como é chamada popularmente onde reside pelos marajoaras da ilha do Marajó $^{4}$, onde até hoje desenvolve um projeto social para crianças carentes, denominado inicialmente de Associação Cultural Caruanas do Marajó, fundada em 21 de julho de 1999, atualmente chamado de Instituição Caruanas do Marajó: Cultura e Ecologia, sediada no município de Soure, localizado na ilha do Marajó, ao Norte do Pará, na Amazônia 5 .

As duas narrativas não trazem, em sua contra-capa ou na capa, o redator ou o tradutor das obras, o que sugere ter sido a própria pajé Zeneida Lima que narrou e escreveu suas memórias, muito embora a mesma manifeste agradecimentos àqueles que, de alguma forma, contribuíram para sua elaboração. Na verdade, nada disso relativiza o valor dessas representações e manifestações simbólicas da pajelança que trazemos aqui como investigação dentro de uma tradução antropológica.

De acordo com o Relato da pajé Zeneida Lima (1992), como ela mesma se denomina, teve sua iniciação ${ }^{6}$ no Pajeísmo ainda criança, realizada pelo Pajé Mestre Mundico do Maruacá, região do município de Salvaterra, na Ilha do Marajó, com duração de um ano e 17 dias, a fim de que todos os rituais e preceitos antigos fossem cumpridos. Nesse momento,

\footnotetext{
${ }^{4}$ A grande ilha do arquipélago do Marajó, é uma das maiores reservas ecológicas do mundo. Soure é um dos 12 municípios da Ilha. A pérola do Marajó situa-se na costa leste, diante da Baía do Marajó, a enorme foz do Amazonas, ao lado da embocadura do Paracauari. (Fonte: O Mundo Místico dos Caruanas, 1992,p.20)

${ }^{5}$ http://www.caruanasdomarajo.com.br/novo/pagina/sec/198/sel/gp. Acesso em 23 set. 2016 (Zeneida também virou tema de filme da cineasta Tizuka Yamasaki, que se prepara para lançar a Amazônia Caruana, baseado no livro de 1993[1992])

${ }^{6}$ Iniciação = Trata do neófito, aquele que recebeu o batismo; noviço; indivíduo admitido em uma corporação.(Dicionário Aurélio da Língua Portuguesa,1986)
} 
Zeneida (1992) aprende sobre o Mundo Encantado e seus mistérios, como as "Sete cidades encantadas" que existem sob o mar e onde vivem os Caruanas. O pajé, Mestre Mundico, instrui e narra a Zeneida sobre o mundo encantado formado por cidades acompanhadas por elementos mágicos que só os Pajés podem ter acesso, tendo sido a mesma conduzida para esse mundo pelo Peixe de Sete Asas Coloridas. Segundo Zeneida (1992, p.27) destaca que cada tribo tem uma maneira de explicar a origem das energias e o Pajeísmo é o encontro do homem com as energias da Natureza, os Encantados ou Caruanas.

O Pajé nada mais é que um instrumento para a manifestação dos Caruanas, considerados energias viventes sob as águas, sendo ele, que propicia a vinda dos Encantados em Terra para auxiliar os viventes em suas doenças ou dificuldades. A pajé Zeneida Lima (1992), ao demonstrar sua fidelidade a esse tipo de manifestação, destaca em sua obra que:

A Pajelança é um culto à encantaria, que herdamos da cultura aborigena ${ }^{76}$ em nossa civilização. Ao incorporar a cultura civilizada sofreu influências das outras culturas colonizadoras e africanas. Perdeu sua pureza de origem. Contudo, eu permaneço fiel aos ensinamentos do pajé que me preparou, mestre Mundico de Maroacá. (1992, p.28)

Sérgio Buarque de Holanda (1973) em sua obra "Raízes do Brasil" relata que índios e colonizadores se comunicaram de forma oral, primeiro com gestos, sendo a língua de contato, o nheengatu, que teve origem do tronco tupi, uma vez que não havia registros de escrita, tornando-se uma língua geral a todos, além de ser falada no litoral brasileiro e que se difundiu na região amazônica. O nheengatu foi uma língua largamente usada pelos colonizadores no Brasil até o século XVIII.

Adentrando no passado histórico, segundo Cavalcante (2008), que os cronistas chegaram à América no século XVI e viam os xamãs dessas terras como práticas demoníacas, cujas práticas eram atribuídas aos índios, que, sob a perspectiva dos colonizadores, eram induzidos pelo próprio demônio representado pela figura do pajé. Quando de suas pesquisas pelo Norte e Nordeste do Brasil e como estudioso da cultura popular, o escritor Mário de Andrade (apud Nogueira, 2007, p.266) conseguiu registrar em fotos, discos, filmes e anotações diretas dentre outras manifestações culturais, o bumba-meu-boi do grupo Boi Bumbá "Pai do Campo", melodias de pajelança e o culto de feitiçaria babaçuê do mestre Sátiro Ferreira de Barros.

Como antropólogo e folclorista, Câmara Cascudo (1956 apud Cavalcante, 2008)

\footnotetext{
${ }^{7}$ Os aborígenes da Austrália descendem de emigrantes africanos que povoaram a Ásia e há 60 mil anos cruzaram o mar, utilizando canoas e toscas embarcações http://www.audacia.org/cgibin/quickregister/scripts/redirect.cgi?redirect=EEuykFFVlpYqDblxRD Acesso em 24 set. 2016
} 
desenvolve uma coletânea acerca do folclore brasileiro, onde se encontram registros de cronistas sobre a prática da pajelança entre os grupos indígenas. Segundo pesquisa de Veronique Boyer(1999), a prática da pajelança foi proibida na cidade de Belém face a uma caracterização errônea de achar que a arte dos pajés havia se tornado 'feitiçaria'. Também Aldrin de Figueiredo (1996 apud Cavalcante, 2008,p.9), ressalta o não reconhecimento dessas práticas à época ao acrescentar que:

Naquela época "a estratégia dos homens de letras foi decretar a morte da pajelança, por não reconhecer nas 'novas' práticas dos pajés de Belém, aquela religião 'primitiva' dos índios da Amazônia" (1996,p.216).[...] Para eles, a arte dos pajés indígenas, que se considerava como uma espécie de medicina primitiva, transformou-se, com a sua passagem para o meio urbano, em pura feitiçaria (1996,p.237).

Na Amazônia, o Xamanismo recebe a denominação de pajelança cabocla, uma vez que a pajelança indígena está em constante processo de mudança desde o processo de ocupação das terras pelo europeu que, ao contatar grupos de origem africana, acaba por resultar em práticas religiosas no Brasil, retratados numa espécie de sincretismo religioso, considerado negativo pelos intelectuais da época, segundo observou Figueiredo ( apud Cavalcante, 2008, p.41). Relata Zeneida Lima que:

\begin{abstract}
Os caruanas são energias viventes sob às águas, conforme a concepção da encantaria cultuada pelos índios marajoaras. Quando as pessoas se encantam, suas energias humanas são levadas para o Patuanu. Lá passam por vários estágios como flor, peixe, ave, etc. Durante esse processo perdem suas energias como viventes e estas se fundem com as energias já existentes sob as águas do mar e que agora podem ser invocadas pelo pajé. A partir daí passam a se chamar caruanas (1992, p.29).
\end{abstract}

Viveiros de Castro (1993) aborda a questão dos pontos de vista não-humanos e da natureza posicional das categorias cosmológicas ao conjunto mais amplo de manifestações de uma economia simbólica da alteridade, onde questiona o fato desse "ver como" se refere literalmente a perceptos ${ }^{8}$, e não analogicamente a conceitos, ainda que, em alguns casos, a ênfase seja mais no aspecto categorial que sensorial do fenômeno; de todo modo, os xamãs, mestres do esquematismo cósmico (Taussig 1987,462-463 apud Viveiros,1996), são dedicados a comunicar e administrar essas perspectivas cruzadas e estão sempre aí para tornar sensíveis os conceitos ou tornar inteligíveis as intuições.

Eu fui contida a custo.[...]Soltava urros e meu rosto ganhou aspecto medonho. Sangue brotou do meu nariz e ouvidos, debatia-me com extrema fúria. Mestre Elpídio (pajé), contemplava o quadro atento[...] - Dona Maria José, isso é flechada

\footnotetext{
${ }^{8}$ Do latim perceptu,percebido,rel. à percepção.(Dicionário Aurélio Buarque,1986)
} 
de Anhangá.[...] É uma dupla energia que protege a Natureza e ao mesmo tempo "flecha"(pune) seus agressores.[...] -Essa menina tem o dom de ser curandeira![...]Ela tem que ser sentada, dona.[...] - Só uma pajelança pode fazer parar essas energias de Anhangá!(LIMA,2001,p.144-145)

Também Lévi-Strauss (2003,cap.IX,p.181) comenta no artigo O feiticeiro e sua magia que:

O fato da mitologia do xamã não corresponder a uma realidade objetiva não tem importância, pois que a paciente nela crê e é membro de uma sociedade que nela crê. Espíritos protetores e espíritos maléficos, monstros sobrenaturais e animais mágicos fazem parte de um sistema coerente que funda a concepção indígena do universo. (LÉVI-STRAUSS, 2003, p.181)

Mircea Eliade ( apud Cavalcante,2008,p.42) descreve os Xamãs como indivíduos dotados de prestígio religioso e ressalta que o termo Xamânico trata-se de um fenômeno religioso de origem siberiana do centro asiático, sendo o xamã o grande mestre do êxtase. A palavra Xamã vem da língua siberiana Tungue e indica o mediador entre o mundo humano e o mundo dos espíritos. Para Jean Langdom (apud Cavalcante,p.43), o xamã tem a missão de mediar os espíritos e os homens, onde essa mediação só é possível através das técnicas de êxtase por ele desenvolvidas como cantos, danças e intoxicação com o único objetivo de garantir a harmonia do grupo. No Brasil o xamanismo é conhecido como pajelança, fenômeno reconhecido pela antropologia como dinâmico e que se tornou material de pesquisa no meio acadêmico.

Desde que chegou aqui,[Mestre Mundico] to trabalhando para a menina. Ela tá cercada pelos seus caruanas. Logo mais vou fazer uma pajelança. A senhora fale com os caruanas. [...] Vamos acabar com isso...(dizia meu pai). Evidentemente, em estado de possessão eu não podia ouvi-lo. Isso é histeria. Acabo agora mesmo com essa caruana. Ali jazia apenas um corpo. Não entendia ele que os limites do corpo são ínfimos em relação à grandiosidade das energias da natureza. (LIMA, 1992,p.128-166)

Uma das definições encontradas para o ritual de pajelança encontra-se em Galvão (1976 apud Maués,1995,p.18), onde afirma que

\footnotetext{
a pajelança trata-se de um culto que tem origem nos grupos tupis e se integra hoje num novo sistema de relações sociais, onde incorporou crenças e práticas católicas, kardecistas e africanas, recebendo atualmente forte influência da umbanda. (LIMA, 1995,p.18)
}

Nas considerações apontadas frente à constatação do sincretismo religioso existente entre a pajelança e a prática da religião católica à época, constata-se o destaque dado a essa simbiose, oriundo talvez das influências culturais vigentes, quando do destaque dado na 
afirmação de que a pajelança era praticada por pessoas que se consideravam "bons católicos" (Galvão apud Maués, 1995,p.17,destaque do autor),onde os pajés e curadores ao presidirem sessões xamanísticas, se deixam incorporar por um tipo especial de entidades (encantados e caruanas). Na concepção de Maués (idem, p.18), a pajelança cabocla trata-se de uma forma de culto mediúnico, constituída por um conjunto de crenças e práticas muito difundidas na Amazônia, com origem na pajelança dos grupos tupis.

Nas narrativas da D. Zeneida Lima (2001, p.144-145), verifica-se a presença e respeito às práticas católicas em consonância com a pajelança cabocla, como a sexta-feira da Paixão de Cristo, que exerce força ideológica e cultural sobre aqueles que se envolvem com o fenômeno:

\footnotetext{
Era uma sexta-feira da Paixão. Os dias grandes eram muito respeitados. Falava-se baixinho, não havia cantoria ou qualquer manifestação de alegria. [...] [Mamãe] no íntimo, não estava convencida dos poderes de Mestre Elpídio, mas não lhe sobravam alternativas. - O Senhor pode fazer essa pajelança hoje? - Hoje não, dona. É sexta-feira Santa. [...] Chegando à capela, mamãe ajoelhou-se diante do altar e persignou-se. Desfiou o padre nosso, credos, salve-rainha, ave-marias e cânticos.[...]São Geraldo ,a quem papai dedicava oito dias de festa por devoção.(LIMA,2001,p.144-186)
}

Sob o olhar da antropologia, ao tratar do perspectivismo ameríndio, o antropólogo e etnólogo Viveiros de Castro (1996) reconhece a presença da mitologia xamã constante de um lugar geométrico, onde a diferença entre os pontos de vista é ao mesmo tempo anulada e exacerbada, em contraponto ao mito, que se reveste então do caráter de discurso absoluto. Segundo Castro (idem), no mito, cada espécie de ser aparece aos outros seres como aparece para si mesma (como humana), e age como se já manifestando sua natureza distintiva e definitiva (de animal, planta ou espírito), onde, de certa forma, todos os personagens que povoam a mitologia são xamãs, o que, aliás, é explicitamente afirmado por algumas culturas amazônicas. Ponto de fuga universal do perspectivismo cosmológico, o mito fala de um estado do ser onde os corpos e os nomes, as almas e as afecções, o eu e o outro se interpenetram, mergulhados em um mesmo meio pré-subjetivo e pré-objetivo - meio cujo fim, justamente, a mitologia se propõe a contar. Verificamos que, sob a perspectiva do conceito do etnocentrismo, Rocha (1988, p.10 )observa que é importante ver as coisas do mundo como a relação entre elas, ou seja, ver que a verdade está mais no olhar que naquilo que é olhado(grifo nosso), e ainda acrescenta que relativizar é não transformar a diferença em hierarquia, em superiores e inferiores ou em bem ou mal, mas vê-la na sua dimensão de riqueza por ser diferença. (grifo nosso) 
A pajelança é o ato final do ritual que começa no dia anterior. Na véspera da pajelança, o pajé mantém-se reservado. A mais das vezes não recebe estranhos. [...] Jejua nesse dia e no dia da pajelança, ou alimenta-se regradamente. Come apenas do peixe, a parte do rabo e quase sem sal. Deve recolher-se com o pôr do sol e levantarse nos primeiros instantes do dia.[...]Falava baixinho, preparando os enrolados de tauari (candeia). O nome de Anhangá sobressaía-se em seu estranho gungunado. (LIMA, 2001,p.149)

Quem cura são os caruanas através do pajé. (LIMA,1992,p.165) [...] e eles são seres encantados, donos dos mistérios do mundo. (LIMA, 1992, p.135)

Se não fosse pelos ataques, a doença inexplicável e o rápido desenvolvimento do meu poder de cura, exercido desde cedo, eu não seria diferente de tantas crianças em minha idade.[...] Aceitei o tratamento de Mestre Elpídio, mas não deseja o "sentamento" para tornar-me pajé. (LIMA, p.166)

Bruna Franchetto (2012) aborda, ao falar de sua experiência na tradução de línguas ameríndias, sobre suas sensações no processo da mutilação da multidimensionalidade da oralidade, ao tentar transpô-las para outra língua distante, ao interpretar conceitos, explanações e histórias de vida. Segundo Franchetto (2012),

[...] a escrita se pretende "civilizatória", aniquila formas e mecanismos de memorização e de transmissão inerentes à oralidade - como já dizia um Platão conservador, quando as Musas aprenderam a escrever - imobiliza o movimento das versões, do dizer, cristaliza palavras e construções.(2012,p.3)

Na narrativa da D. Zeneida(1992) verificamos o destaque dado à dificuldade no entendimento pelos humanos frente às mensagens dos caruanas ou não-humanos, no que diz respeito ao discurso e linguagem empregadas na oralidade por essas entidades cosmológicas. A pajé Zeneida (1992), no contexto da pajelança cabocla, enfatiza ao Mestre Mundico, a necessidade do transmissor $^{9}$ (Lima,1902,p.39, grifo nosso), junto ao pajé (médium),como sendo aquele que traduz a língua dos encantados ou caruanas ou não-humanos para o entendimento dos homens que habitam a terra. Quem já teve a oportunidade de assistir algum tipo de manifestação mediúnica em terreiros de umbanda ou de sessões voltadas para o espiritismo, certamente que pode presenciar esse tipo de "intermediário"(grifo nosso) entre as duas linguagens.

- É um encantado do Guajará.[...] um caruana que vive nos quatro lados do mundo.[...]Num lado ficam as pessoas da terra, em outro, as plantas, no terceiro fica a encantaria e no quarto lado se encontram os animais.[...]Mamãe sentiu-se angustiada por não alcançar o rela sentido da mensagem[...].(LIMA, 1992,p.135)

- D.Zeneida, por que a senhora precisa de um transmissor ${ }^{8}$ ? $\quad$-Sr. Gustavo, eu preciso de uma pessoa que me transmita os recados dos caruanas, isto é, um homem

\footnotetext{
${ }^{9}$ Transmissor $=$ tem o sentido de Tradutor. Trata-se de alguém que traduz o discurso do Pajé, procedimento esse comum também nos terreiros de Umbanda, com os acompanhantes(tradutores) dos "cavalos"(médiuns) que recebem as entidades(observações nossa constatadas em um terreiro de Umbanda na Cidade Nova, nas cercanias da cidade de Belém)
} 
de confiança. [...]Se a pessoa não for de confiança, poderá me dizer mentiras, algo que os caruanas não tenham falado, e eu poderia acreditar, pois quando me atuo, não vejo nada.(LIMA,1992,p.39)

Todos os seres vêem [...]o mundo da mesma maneira - o que muda é o mundo que eles vêem", e acrescenta - "o que parece se afirmar entre os índios é, antes, a multiplicidade radical do mundo, sua insubmissão a qualquer forma de monarquia ontológica(LIMA, 2012, p.141).

Fica claro no perspectivismo multinatural, a posição de respeito às diferenças e não a busca de identidades frente à tradução. Diante das narrações e manifestações da pajelança cabocla relatadas por Zeneida Lima $(1992 ;$ 2001), frente às reflexões de Viveiros de Castro(2012), tais fenômenos nos levam a buscar formas de pensar centradas em Walter Benjamin(apud Branco,2008,p.51),quando nega qualquer possibilidade de aprofundamento do conhecimento, quando a obra de arte leva em conta o receptor ideal, uma vez que essa só pressupõe a existência e a essência do homem em geral. Entendemos que na concepção de Benjamin (idem, 2008, p.54), a tradução não pode, por si só, manifestar e restituir essa relação oculta dentre línguas, uma vez que a vida não verbal conhece como analogias e signos, outros tipos de referência que não a atualização intensiva, isto é, antecipadora e anunciadora. $\mathrm{Na}$ verdade, Benjamin (2008) ressalta a importância da linguagem quando da busca da afinidade entre duas línguas, diante do fato de que elas são complementares e se tornam única, quando da exclusão de palavras, frente à chegada da nova língua oriunda da tradução, apreensões essas mescladas pela filosofia da linguagem retratada o-que-se-significa (Gemeine) e do modo de significá-lo (die Art des Meinens). Segundo George Steiner (2005, p.72), o fato de que milhares e milhares de línguas diferentes e mutuamente incompreensíveis foram e são faladas em nosso pequeno planeta é uma expressão clara do enigma profundo da individualidade humana, da evidência biogenética e bissocial de que não existem dois seres humanos inteiramente iguais. Na concepção de Steiner (idem), o evento de Babel confirmou e externalizou a interminável tarefa do tradutor (grifo nosso).

Também Evelyn Zea (2008, p.2) busca amparo nas ideias alternativas de vários teóricos como Lawrence Venuti, Antonio Berman, Walter Benjamin e Georg Steiner para ressaltar a desconstrução das idéias pré-concebidas sobre a tradução e aponta questionamentos sobre a gênese que trata da autoria e origem da tradução.

Questões sobre propriedade e impropriedade em uma tradução são levantadas por Zea (2008), dando ênfase ao caráter genitivo ${ }^{10}$ no campo semântico da palavra gen, expressos no objetivo, subjetivo e intersubjetivo, caracterizado na própria relação que a tradução

\footnotetext{
${ }^{10}$ Genitivo = Caso de declinação de certas línguas, que representa, por via de regra, complemento possessivo, limitativo, e, algumas vezes, circunstancial.
} 
estabelece, retratado na neutralidade que tradutor e linguagem repassam quando da concretização de uma tradução.

Segundo Zea (2008) enfatiza que, isso se dá em razão da tradução trazer embutida na sua metodologia e concepção valores da cultura ocidental retratados em pressupostos ideológicos, mistificações e contradições referentes a seu modo de operação e rendimento. Para evidenciar esses fenômenos, o autor ainda aponta questões que contribuíram para a forma como a tradução era concebida, dentre elas as técnicas e estratégias editoriais, somada à própria "unilateralidade" da tradução segundo a qual as línguas e as traduções são elementos estanques e externos, um ao outro. Tais processos resultaram no obscurantismo da figura do tradutor e na marginalidade da própria linguagem. Para isso, Zea (2008,p.2) retoma a ideia de Venuti (1995) ao afirmar que a visibilidade da fonte é inversamente proporcional à visibilidade da tradução, ou seja, a revelação de uma demanda a retração da outra. O que nos faz lembrar das palavras de Venuti em seu livro Escândalos da tradução, (2002 apud Narceli Piucco,2008,p.180), ao classificar os escândalos em culturais, econômicos e políticos. Segundo Venuti,

as traduções[...], em outras palavras, inevitavelmente realizam um trabalho de domesticação. Aquelas mais poderosas em recriar valores culturais e as mais responsáveis para responder por tal poder, geralmente engajam leitores graças às palavras domésticas que foram, de certo modo, desfamiliarizadas e se tornaram fascinantes devido a um embate revisório com o texto estrangeiro. (apud ZEA, 2008, p.18)

Quando Zea (idem, ibidem) toma a Tese sobre a Tarefa do Tradutor de Benjamin para, junto ao modelo waiwai, justificar que a tradução aparece como sobrevivência do original, acabou por nos levar a refletir sobre tais processos diante da pajelança cabocla, tão aclamada pela pajé Zeneida Lima, quando ela “recebe” em sessões 'mediúnicas' entidades ou seres não humanos, denominados de caruanas ou encantados, entrando num processo de transmutação, transe e êxtase, traduzida numa dimensão cosmológica, se assim podemos transcrever esse processo de inquietação da existência e, porque não dizer, retomando as palavras de Zea (Idem,p.68-69), numa tradução 'intersubjetivo', quando de relações com humanos ou nãohumanos, resultando num processo de renovação e transformação gerada pela tradução, pensamento esse ratificado em Derrida(1972,p.31 apud Zea,2008,p.75), ao afirmar que a tradução equivale decididamente a um processo de transformação.

Por conseguinte, Paul De Man (1989, p.109), ao tentar interpretar as palavras de Walter Benjamin no ensaio A Tarefa do Tradutor( 1989), acrescenta que a linguagem tem importância fundamental no olhar benjaminiano, bem como, afirma que "o tradutor tem de 
desistir da tarefa de redescobrir o que estava no original", o que vem se somar às ideias de Zea (Idem,p.122) quando ressalta estar Paul De Man sugerindo a descanonização do original e, por extensão, de toda a instância absoluta no processo de tradução, retratado na afirmação de De Man(Idem,p.111) de que:

[...] tanto a crítica como a tradução são apanhadas na atitude a que Benjamin chama irônica, uma atitude que desfaz a estabilidade do original, dando-lhe uma forma canônica definitiva na tradução ou na teorização.(1989, p.111)

Após todas as reflexões voltadas para o conceito de tradução na antropologia, retomase o ritual da pajelança cabocla da pajé Zeneida Lima (1992;2001), assim pode-se levantar algumas observações com o caráter de transformação durante o processo de manifestação dos caruanas ou encantados, onde a autora é o fio condutor da língua dos não-humanos para o humano, passando ainda por um tradutor, a pessoa que ouve a pajé(esta sob o efeito mediúnico ou de transe) e traduz a linguagem do não-humano para o humano, fato esse registrado na narrativa de Zeneida ao se referir ao vocábulo 'Transmissor'(Lima, 1992, p.39).

Ao voltarmos nossos olhos para a pajelança cabocla na Amazônia e suas particularidades, lembramos que o grande antropólogo alemão Franz Boas(1964) observou nas suas reflexões que tudo é produto de contexto social, cultural e histórico, onde tudo se resume em transferências, no seguinte:

\footnotetext{
devemos ter presente que nenhuma dessas civilizações foi produto do gênio de um só povo. Ideias e invenções passaram de uns a outros; e embora a comunicação recíproca fosse lenta, cada um dos povos que participaram da cultura antiga contribuiu com seu aporte ao progresso geral.[...] Nem raça e nem idioma limitam sua propagação. A hostilidade e a tímida repulsa feitas por vizinhos não conseguem impedir que fluam de tribo a tribo e se filtrem através de distâncias que se medem por milhas e milhas.(1964,p.23)
}

Com base nas pesquisas e fundamentações de teóricos aqui citados unido à reflexão de Franz Boas(1964), podemos observar a constatação de ilimitados entrecruzamentos de vetores sociais com processos de transferência e dimensão cultural, dos quais os fenômenos mediúnicos relatados pela pajé Zeneida Lima em suas narrativas (1992; 2001),encontram-se caracterizados nos discurso e linguagem advindos dos seres não-humanos, denominados de caruanas ou encantados, e traduzidos para os humanos, com o tradutor denominado de “transmissor" na narrativa da pajé Zeneida Lima(1992), cujo diálogo nem sempre se concretiza, fazendo com que a tradução ganhe uma nova dimensão, a da flutuação e da imprecisão, resultando em um campo aberto, denominado por Venuti (1995), de campo da não domesticação do discurso. 


\section{REFERÊNCIAS}

BRANCO, Lucia Castello(Org.). A tarefa do Tradutor, de Walter Benjamin: quatro traduções para o português. Belo Horizonte, 2008.

BOAS, Franz. Cuestiones Fundamentales de Antropologia Cultural. .Solar/Hachette,1964.

BUARQUE, Aurélio. Novo Dicionário Aurélio da Língua Portuguesa. 2ª́Edição.Nova Fronteira, 1986.

BOYER, Véronique. O pajé e o caboclo:de homem a entidade. Scielo. Mana. vol.5, $\mathrm{n}^{\circ} 1$, Rio de Janeiro.Abril,1999.

CAVALCANTE, Patricia Carvalho. De "nascença" ou de "simpatia, iniciação, hierarquia e atribuições dos mestres na pajelança marajoara. Dissertação de mestrado em Ciências Sociais. Belém/Pará.2008,104p.

CASTRO, Eduardo Viveiros de. Os pronomes cosmológicos e o perspectivismo ameríndio. Mana,Sielo,vol.2,n².Rio de Janeiro, Outubro, 1996.

DERRIDA, Jacques. Torres de Babel. Tradução de Junia Barreto. Belo Horizonte, UFMG, 2002.

DE MAN, P. Conclusões “A tarefa do tradutor" de Walter Benjamin. Tradução de Teresa Louro Pérez. In. A resistência à teoria. Lisboa \& Rio de Janeiro, Edições 70,1989.

ELIADE, Mircea. O Xamanismo e as técnicas arcaicas do êxtase. Tradução de PerroneMoisés, B. Benedetti, I.C.S.P.: Martins Fontes, 2002.

FIGUEIREDO, Aldrin Moura. A cidade dos Encantados: pajelança, feitiçaria e religiões afrobrasileiras na Amazônia 1870-1950. EDUFPA:2009.199p.

FRANCHETTO, Bruna. Línguas Ameríndias: Modos e Caminhos Da Tradução. Museu Nacional/Universidade Federal do Rio de Janeiro, 2012.

HOLANDA, Sérgio Buarque. Raízes do Brasil. Rio de Janeiro: José Olympio,1973.

LÉVI-STRAUSS, C. O feiticeiro e sua magia, $6^{\mathrm{a}}$ ed. In: Antropologia Estrutural. Tradução Leila Perrone Maués. Rio de Janeiro. Tempo Brasileiro, 2003, p. 181-200

LIMA, Zeneida. O Mundo Místico dos Caruanas e a Revolta de sua Ave. Belém: Cejup, 1992. 288p.

2001.419p.

O Mundo Místico dos Caruanas na Ilha do Marajó. Belém: Cejup,

LOUREIRO, João J. P. Cultura Amazônica:uma poética do imaginário. Belém, Cejup, 1995. 448p.

MAuÉS, R. H. Padres, Pajés, Santos e Festas. Catolicismo Popular e Controle 
Eclesiástico. Um estudo antropológico numa área do interior da Amazônia. Belém: Cejup,1995.

MARTINS, Helena Franco. Tradução e Perspectivismo/Translation and perspectivism. Revista Letras, Curitiba, n. 85, p. 135-149, jan./jun. 2012. Editora UFPR. ISSN 0100-0888 (versão impressa); 2236-0999 (versão eletrônica 136).

NOGUEIRA, A. G. R. Inventário e patrimônio cultural no Brasil. História, v. 26, n. 2, São Paulo, 2007, p. 257-268.

PIUCCO, Narceli. Sobre a (in)visibilidade do tradutor na tradução: algumas referências teóricas e opiniões de tradutores literários. Revista Trama - Volume 4 - Número 7 - $1^{\circ}$ Semestre de 2008 , p.177-187.

ROCHA, Everardo G. R. O que é Etnocentrismo?.5ªd. São Paulo: Brasiliente,1988.

STEINER, George. Depois de Babel. Questões de Linguagem e Tradução. Trad. Carlos Alberto Faraco, 3 ed. Curitiba: Editora UFPR, 2005.

STRAUSS, Claude Lévi. Antropologia Estrutural. Tradução Beatriz PerroneMoisés.Cosacnaify, 1958.

VENUTI, Lawrence. The Translator's Invisibility. A History of Translation. London and New York. Routledge. 1995.

ZEA,Evelyn. Genitivo da Tradução. Bol. Mus. Pará. Emílio Goeldi. Ciências Humanas, Belém, v. 3, n. 1, p. 65-77, jan.-abr. 2008. 